\title{
0 conceito de geoparque no Brasil: reflexões, perspectivas e propostas de divulgação
}

\author{
The Geopark Concept In Brazil: Reflections, Perspectives And Scientific Divulgation
}

\author{
Silvio Yuji Onary-Alves ${ }^{1}$ Bruno Becker-Kerber ${ }^{2}$, Priscila dos Reis Valentin ${ }^{3}$, Mírian Liza Alves Forancelli Pacheco ${ }^{4}$ \\ 1 Prog. Pós-Grad. Em Biologia Comparada. FFCLRP - USP, Departamento de Biologia. Ribeirão Preto, SP - silvioyuji@gmail.com \\ 2 Progr. Pós-Grad. Geoq. e Geotect. USP, Inst. Geoc., Depto. Geol. Sed. e Ambiental. São Paulo, SP. \\ 3 Graduanda em Ciências Biológicas, Univ. Fed. São Carlos - Campus Sorocaba. Sorocaba, SP. \\ 4 Departamento de Biologia, Univ. Fed. São Carlos - Campus Sorocaba. Sorocaba, SP.
}

\section{Manuscrito: \\ Recebido: 10/03/2014 \\ Corrigido: 21/04/2015 \\ Aceito: 29/04/2015}

Citation: Onary-Alves S.Y., Becker-Kerber B., Valentin P..R., Pacheco M.L.A.F.2015. 0 conceito de geoparque no Brasil: reflexões, perspectivas e propostas de divulgação. Terræ Didatica, 11(2):94-107. <http://www.ige.unicamp.br/ terraedidatica/ $>$.

Keywords: Geoparks, Geoconservation, Divulgation in paleontology, Bodoquena-Pantanal Geopark, Araripe Geopark.

\begin{abstract}
Geopark is a concept assisted by UNESCO to demarcate areas with outstanding landscape, human populations and geological heritage in a context of sustainable development. Worldwide, the concept is well disseminated. However in Brazil this concept still not widespread. This work reflects and discusses the concept by the means of comparisons with international successful programs with one of the candidate areas in Brazil, "Geopark Bodoquena Pantanal" - MS, and also proposes didactic materials that can be used to scientific divulgation purposes. The concession on the Global Geoparks Networks is an important key to economic and scientific development, however it is necessary a well elaborated management and an interdisciplinary effort. The Geopark Araripe (the only in Brazil) shows a great work even with problems like poverty and fossil trafficking. The candidate Bodoquena-Pantanal has some regions that contain population that doesn't know the real concept of a geopark initiative and it is necessary better works on educational aspects.
\end{abstract}

\section{Introdução}

Um grande desafio a ser superado no Brasil é a necessidade de políticas voltadas para educação patrimonial e medidas que visem a geoconservação. Essa lacuna dificulta a conscientização da população frente sua memória cultural e desenvolvimento sustentável (Brilha 2009, Bacci et al. 2009, Piranha e Lama 2011).

Neste contexto, surge o conceito de geoparque: estratégia territorial com limites definidos, destinado a práticas de geoconservação e desenvolvimento econômico sustentável das cidades envolvidas. Deve conter elementos de grande valor geológico, paleontológico ou arqueológico, apelo cênico, expressiva biodiversidade e potencial turístico, não sendo, no entanto, caracterizado como uma área de proteção ambiental legal (Zouros 2004, McKeever e
Zouros 2005, McKeever et al. 2010, Unesco 2010, Silveira et al. 2012).

No modelo ideal de funcionamento (sensu UNESCO 2010), as comunidades humanas sob influência do geoparque devem possuir pleno conhecimento a respeito da proposta, interagindo com o contexto da geodiversidade, propostas de desenvolvimento econômico sustentável e projetos educacionais, os quais podem transformar o geoparque em extensão econômica e cultural das cidades adjacentes (Eder 2004, Brilha 2009, Boggiani 2010a, Silveira et al. 2012).

A interação entre geoparques e comunidade ultrapassa as barreiras sociais, uma vez que mobiliza ONGs, órgãos nacionais, federais, setor privado, e, em alguns casos, o governo nacional no processo de implementação e desenvolvimento (Eder 2004, Brilha 2009, Duarte 2011). 
O termo "geoparque" (sensu UNESCO 2010) constitui um conceito apoiado pela UNESCO. Contudo, não há impedimentos na utilização desse nome por terceiros. Usualmente, "geoparque" é uma palavra empregada no Brasil para a designação de sítios de amplo interesse geológico e paleontológico.

Trabalhos desenvolvidos pela Companhia de Recursos Minerais (CPRM) (Schobbenhaus e Silva 2012) e Comissão Brasileira de Sítios Geológicos e Paleobiológicos (SIGEP) (DNPM, CPRM e SIGEP 2002) exemplificam esse uso do termo "geoparque" de um modo distinto do "geoparque" (sensu UNESCO 2010).

Contudo, é válido lembrar que o termo "geoparque" sensu CPRM e SIGEP não parte dos pressupostos de estratégia territorial de um geoparque sensu UNESCO (2010), explanada e adotada como eixo central no presente trabalho.

O selo de "Geoparque" depende de uma série de critérios estabelecidos por diretrizes específicas, sujeita à avaliação e consentimento da UNESCO (Eder 2004, McKeever et al. 2010, UNESCO 2010). Com a obtenção, há a inclusão da área na Rede Mundial de Geoparques (Global Geoparks Network - GGN) e o território passa a ser avaliado pela UNESCO a cada quatro anos, sendo passível de revogamento (Zouros 2004, Duarte 2011).

A proposta da criação da GGN é relativamente nova: foi a partir de 2004 que a UNESCO iniciou a estruturação do projeto por meio do reconhecimento de 77 geoparques mundiais, em 25 países (UNESCO 2010). Essa iniciativa foi oriunda de diversas discussões das comissões da Rede Europeia de Geoparques (previamente estabelecida na Europa), a qual, em acordo oficial com a Divisão das Ciências da Terra da UNESCO e o conselho Europeu, inauguraram a Rede Mundial (Zouros 2004, Brilha 2009, Mckeever et al. 2010).

O Geoparque Araripe, entre os estados do Ceará, Piauí e Pernambuco, é o único do Brasil e das Américas (Duarte 2011, Silveira et al. 2012). Existem muitas outras localidades brasileiras com potenciais geossítios (Rocha-Campos 2002, Ribeiro 2011, Rolim 2010). Porém, problemas de cunho político, desconhecimento das práticas geoconservacionistas, defasagem de projetos educacionais e a falta de interação com a comunidade, ocasionam uma cascata de eventos que impossibilitam sua consolidação (Bacci et al. 2009).

Diante do exposto, este trabalho tem por objetivo refletir sobre o conceito de geoparque no Brasil, e discutí-lo sob a perspectiva das áreas brasileiras de interesse para a conservação e desenvolvimento sustentável (e.g. Geoparque do Araripe, CE; e a área candidata Bodoquena-Pantanal), comparativamente ao Geoparque Arouca (modelo Europeu mundial), segundo as diretrizes da UNESCO. Este trabalho ainda inclui material de divulgação científica que pode ser utilizado por profissionais que trabalham na área da educação. Para tanto, ao final do artigo, foi produzido um material lúdico para a divulgação de conhecimentos específicos acerca da Paleontologia da área candidata a geoparque Bodoquena-Pantanal, que também pode ser utilizado em sala de aula em diversas partes do Brasil.

\section{Métodos e motivação}

Foi realizado um levantamento bibliográfico que serviu como base para escolha e comparação entre os geoparques contemplados neste trabalho. A escolha das áreas para comparações foi consolidada com base no critério de funcionalidade, dinâmica e problemática. Desta forma, foram selecionados (1) um modelo ideal de geoparque no exterior, representado pelo Geoparque Arouca, localizado na região de Concelho de Arouca, Portugal; (2) o único geoparque do Brasil, o Geoparque Araripe; e (3) uma área ainda candidata, Bodoquena-Pantanal, que, por uma série de motivos, ainda não recebeu a marca da Rede Mundial de Geoparques, pela UNESCO.

Um dos pressupostos básicos, presente nas diretrizes especificadas pela UNESCO, é a inclusão social das comunidades na área candidata. Para a verificação das interações entre as comunidades e o geoparque, foi utilizado como estudo de caso o Ecoparque Cacimba da Saúde, Corumbá, MS (inserida na área candidata Bodoquena-Pantanal). Nesse local foram realizadas entrevistas semiestruturadas (no formato de conversas informais), em agosto de 2013.

O público alvo foram os residentes do próprio parque, com o intuito de se obter informações legítimas, evitando, assim, entrevistas com turistas, ou outras pessoas que não habitassem o local. As questões construídas tiveram por objetivo extrair informações referentes a opiniões diversas dentro da temática de geoparques, como a definição, funcionalidade, a importância, impacto na vida das pessoas e o discernimento sobre a importância dos patrimônios paleontológico e arqueológicos. 


\section{Relato sobre a visita ao Ecoparque Cacimba da Saúde}

Nove pessoas foram entrevistadas, totalizando quarenta e três minutos de conversa. Destas, oito indicaram que habitavam a região há, pelo menos, vinte anos. Em alguns casos havia moradores da terceira geração da família.

As atividades econômicas da região se baseiam na agricultura e na pesca. Quatro dos entrevistados alegaram trabalhar em atividades relacionadas à agricultura, e cinco, em atividades de pesca, para fins de subsistência. A maioria mencionou possuir "condições boas" de vida, com exceção de um indivíduo, que relatou haver falta de infraestrutura, muito lixo na região e, consequentemente, baixa qualidade de vida. Cinco entrevistados afirmaram ter muita "movimentação" na "Cacimba". Contudo, apenas dois entrevistados mostraram conhecer o envolvimento de cientistas e pesquisas associadas à região, ainda que não soubessem, de fato, o que significava.

Apenas três pessoas entrevistadas confirmaram o conhecimento a respeito de fósseis, sobretudo o metazoário Corumbella werneri (Hahn et al. 1982, Babcock et al. 2005, Pacheco et al. 2011), uma das espécies símbolo do candidato a geoparque Bodoquena-Pantanal. Porém, tal discernimento era restrito apenas ao nome do mesmo. Este animal foi descrito como um cnidário cifozoário datado em ca. 543 Ma. (Ediacarano, Grupo Corumbá). É considerado um dos primeiros animais capazes de realizar esqueletogênese, compondo, juntamente a outros fósseis como Cloudina lucianoi, o último momento evolutivo da Biota de Ediacara (Pacheco et al. 2011, Kerber et al. 2013).

Da totalidade dos entrevistados, sete não possuíam conhecimento a respeito da implementação de um geoparque na localidade, muito menos sobre o termo em si, alegando nunca terem ouvido falar ou, até mesmo, confrontando essa informação como falsa. Apenas dois entrevistados alegaram ter ciência da implementação de um geoparque na região. Por outro lado, desconheciam o projeto em si e não possuíam informação suficiente sobre proposta, conceito, e funcionalidade de um geoparque.

Uma pessoa definiu o geoparque como "uma reserva para a proteção dos animais", enquanto outra interpretou o geoparque como "uma ameaça à desapropriação dos moradores, seguida da construção de hotéis para o turismo". Por fim, sete dos entrevistados afirmaram que a comunidade é unida.
Todos possuem o conhecimento de todos os integrantes e se auxiliam em atividades, como agricultura, pesca e na dinâmica cotidiana da comunidade.

Com a finalidade de se atenuar a problemática no âmbito da falta de conhecimento encontrado na região da Cacimba (Corumbá-MS), e com o intuito de oferecer um material de apoio para educadores e profissionais que trabalham com divulgação em Geociências, foram elaborados cartazes informativos, histórias em quadrinhos e textos de apoio. Estes materiais podem ser utilizados tanto em sala de aula quanto em museus e outros espaços de ensino-aprendizagem, para disseminação de conteúdos específicos da Paleontologia e da temática de geoparques.

\section{Discussões, reflexões e perspectivas}

\section{Diretrizes específicas da Rede Global de Geoparques (GGN)}

O patrimônio paisagístico, geológico, paleontológico e arqueológico possui grande influência nas diversas sociedades humanas, e, embora a Convenção Mundial da Herança reconheça diversos geossítios com grande importância, nunca houve critérios específicos para a determinação das áreas com potencial de preservação (Unesco 2010). Com a finalidade de sanar essas deficiências, foi iniciado em junho de 2001 o programa de suporte a geoparques com o auxílio da UNESCO, visando identificar e transformar áreas com potencial interesse para as geociências, em locais delimitados, nos quais funcionariam um sistema baseado na Educação Ambiental (EA), Patrimonial (EP) e o desenvolvimento econômico sustentável a favor da geopreservação (Unesco 2010).

As áreas destinadas à criação de um geoparque devem ser necessariamente locais com dimensões suficientes para abarcar a integração da biodiversidade, geodiversidade e cultura, podendo, às vezes, ultrapassar limites estaduais. Junção que, consequentemente, acaba por propiciar aos visitantes, conhecimento para que seja desenvolvida a EA e EP, despertando a consciência da conservação de identidade cultural e ambiental.

A área candidata à obtenção do selo deve possuir um grupo responsável pelo manejo (e.g. pesquisadores, financiadores, autoridades e educadores), implementando projetos a curto e longo prazo. As atividades de extensão e educação devem 
ser efetivas, por meio da divulgação das pesquisas científicas para o público leigo. A socialização pode ser feita a partir da criação de museus, visitas guiadas, materiais didáticos ou via mídias digitais (Unesco 2010).

Essa dinâmica contribui para a conservação biológica, cultural e geológica, a partir do momento em que se impulsiona na região o desenvolvimento econômico sustentável e o incentivo para a pesquisa e a prática educativa. As diretrizes possuem papel essencial no manejo de geoparques, pois o não cumprimento de seus critérios pode acarretar em negação ou revogação do selo (Unesco 2010).

\section{0 modelo ideal: Geoparque Arouca (Concelho Arouca - Portugal)}

O Geoparque Arouca apresenta um importante registro fossilífero e geológico, em âmbito mundial (Rocha et al. 2008, Boggiani 2010b). Está inserido na região de Concelho Arouca (distrito de Aveiro, norte de Portugal) (Fig. 1) e enquadra um dos mais bem fundamentados geoparques da Rede Mundial (Rocha et al. 2008, Geopark Arouca 2013).

A geologia da região é a dominada pelo Supergrupo Dúrico Beirão (Neoproterozoico - Cambriano Inferior) e logo acima, encontram-se, em discordância, três formações ordovicianas (Rocha et al. 2008). Destas, destaca-se a Formação Valongo que contém a famosa ocorrência das "Pedras-Parideiras": fenômeno caracterizado pelo desprendimento de nódulos de biotita a partir de uma rocha-mãe (fato popularmente interpretado como uma forma de "parir" a rocha) (Rocha et al. 2008, Boggiani 2010b).

No âmbito sedimentológico, estratigráfico, e, sobretudo, paleontológico, destaca-se o geossítio "Icnofósseis da área de Meitriz", situado nas duas margens do rio Paiva, que contém grande variedade e predominância de icnofósseis (Geopark Arouca 2013). Entretanto, dentre os registros paleontológicos de maior destaque, estão alguns dos maiores trilobitas do mundo, encontrados na "Pedreira de Valário”, em Canelas (Sá et al. 2006, Boggiani 2010b).

Os registros de trilobitas usualmente são de indivíduos menores a $30 \mathrm{~cm}$. Contudo, no local, os exemplares podem chegar a $45 \mathrm{~cm}$ (Gutiérrez-Marco et al. 2009). Esses registros compõem uma janela tafonômica (fósseis com excelente estado de preservação) que revelam aspectos importantes sobre os modos de vida, habitat e paleoambiente (Gutiérrez-Marco et al. 2009).

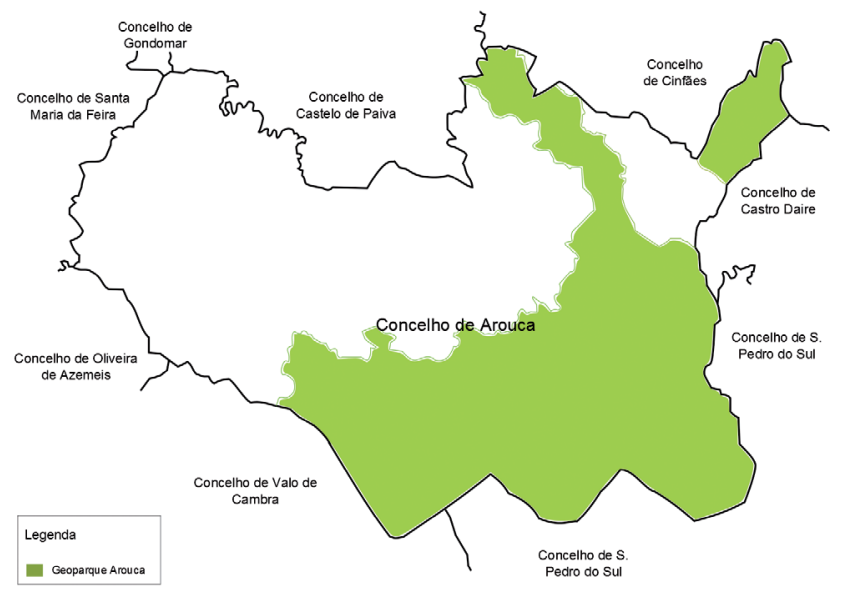

Figura 1. Mapa esquemático do Geoparque Arouca, evidenciando a posição relativa da delimitação do geoparque nas regiões de Portugal. Desenho de Priscila Valentin. Modificado de Geoparque Arouca, 2013.

O Geoparque Arouca foi fundado em meados de 2006, pela câmara municipal de Arouca, e efetivado por meio de uma equipe multidisciplinar de geocientistas espanhóis e portugueses (Rocha et al. 2008, Boggiani 2010a). O geoparque contém 41 geossítios, em uma área de $328 \mathrm{~km}^{2}$, administrados pela entidade AGA- Associação Geoparque do Arouca. A AGA possui o principal objetivo de tornar esta área um território eficaz para a conservação biológica, geoconservação e desenvolvimento social, utilizando a beleza paisagística como um forte aliado para tais finalidades (Geopark Arouca 2013).

Para o desenvolvimento econômico sustentável, o Geoparque do Arouca incentiva o setor hoteleiro, com a produção de adereços inspirados em etnografia, artesanato e gastronomia (Boggiani 2010c, Geopark Arouca 2013). Nas imediações, especificamente onde ocorrem os trilobitas, opera uma grande mineradora de ardósia, que propiciou a criação de um auditório para a exposição dos fósseis e palestras a respeito da Paleobiologia e Geologia (Boggiani 2010a), exemplificando como a geoconservação pode se estabelecer juntamente com o desenvolvimento econômico e educacional (Boggiani 2010a).

O Geoparque Arouca recebe, em média, a visita de cinco mil alunos por ano. As visitas são monitoradas por meio de palestras, trilhas e minicursos, potencializando e divulgando o conhecimento em Geociências (Boggiani 2010a, Geopark Arouca 2013).

No âmbito educativo, a AGA dispõe de duas metodologias: "O geoparque vai à escola" e "A 
escola vai ao geoparque". Na primeira, especialistas coordenam visitações a escolas, ministrando palestras, aulas e minicursos para os alunos. Em outra, ocorre a movimentação inversa, por meio de visita guiada pelos monitores, que ilustram e caracterizam os conteúdos explanados (Rocha et al. 2011).

Atualmente, o Geoparque Arouca investe na disseminação via mídias digitais, como sites e páginas em redes sociais. Este modo de transmissão de conteúdo é, facilmente acessível e contribui para a educação fora dos limites físicos do geoparque.

O turismo em Arouca é recorrente em diversas épocas do ano, e contribui para o desenvolvimento econômico da região, a partir da utilização dos hotéis e pelo consumo de produtos tradicionais, tais como: pão de ló, doces portugueses, broa de milho e a o prato típico de carne de gado Arouquês (Boggiani 2010a, Geopark Arouca 2013).

Essa interação entre educação, divulgação científica, conservação e desenvolvimento econômico sustentável da região, ocorre de maneira sinérgica e faz com que o Geoparque Arouca seja reconhecido como um dos melhores geoparques, exemplificando a importância e os benefícios de uma organização altamente estruturada (Boggiani, 2010a, Rocha et al. 2011).

\section{0 caso brasileiro: Geoparque Araripe (Ceará, Pernambuco e Piauí)}

O Geoparque Araripe é o único geoparque do Brasil. Está localizado no nordeste, na divisa dos estados do Ceará, Pernambuco e Piauí, na Bacia do Araripe (Fig. 2). Encontra-se num território de $3.796 \mathrm{~km}^{2}$, e engloba partes de seis municípios:

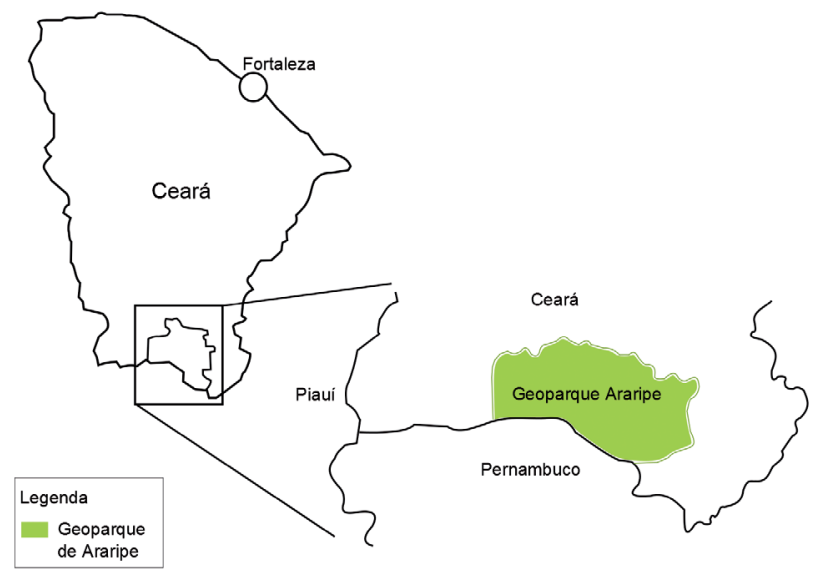

Figura 2: Mapa esquemático do Geoparque Araripe, evidenciando a localização relativa do geoparque entre os estados do Ceará, Pernambuco e Piauí. Desenho de Priscila Valentin. Modificado de Geopark Araripe 2013.
Juazeiro do Norte, Barbalha, Missão Velha, Crato, Santana do Cariri e Nova Olinda (Silveira et al. 2012, Vilas-Boas 2012).

Sua administração atua na conservação de cinquenta e nove geossítios, dentre os quais, nove se apresentam com prioridade de manejo devido aos patrimônios paleontológico e arqueológico (geotopes) (Geopark Araripe 2013). As localidades apresentam estratos correspondentes a intervalos específicos do tempo geológico, auxiliando-pesquisadores, estudantes e visitantes na compreensão da evolução da Bacia do Araripe (Alves et al. 2011).

O geoparque possui um inestimável registro fossilífero do Cretáceo Inferior (Vila-Boas 2012), o que viabiliza importantes estudos paleobiológicos, evolutivos e sistemáticos, auxiliando interpretações e reconstituições sobre a história da Terra.

A peculiar forma de fossilização é oriunda de condições paleoambientais estritamente relacionadas a eventos geológicos (Alves et al. 2011, Vilas-Boas 2012). Nesse quesito, destaca-se a Formação Santana, constituída pelos membros Crato e Romualdo (Alves et al. 2011, Vilas-Boas 2012). Nela são encontrados fósseis de plantas, artrópodes, anfíbios, penas de aves, moluscos, peixes, dinossauros terópodes, e a maior concentrações mundial de pterossauros (Bacci et al. 2009, Vilas-Boas 2012).

O Geoparque Araripe possui como principal objetivo promover o desenvolvimento da região metropolitana do Cariri, seguindo as diretrizes da UNESCO (Vilas-Boas 2012). O mesmo desenvolve na região uma série de programas educacionais, incentivando tanto a pesquisa regional quanto o estabelecimento de atividades econômicas, como, por exemplo, o setor do turismo (Vilas-Boas 2012). Outra característica encontrada nas imediações do Geoparque Araripe é a conservação da biodiversidade e seus recursos naturais que, juntamente com a beleza cênica, promove o ecoturismo local (Vilas-Boas 2012).

No âmbito econômico, o geoparque se sustenta a partir de parceiros dos setores públicos e privados, como o governo federal, as prefeituras municipais e diversas indústrias que apoiam o desenvolvimento das localidades (Geopark Araripe 2010, Silveira et al. 2012, Vilas-Boas 2012).

A principal ferramenta de educação da região é o Museu de Paleontologia da Universidade Regional do Cariri (URCA), que investe na divulgação científica, aproximando estudantes à ciência da Paleontologia, realizando campanhas que incentivam a visitação e conhecimento da comunidade 


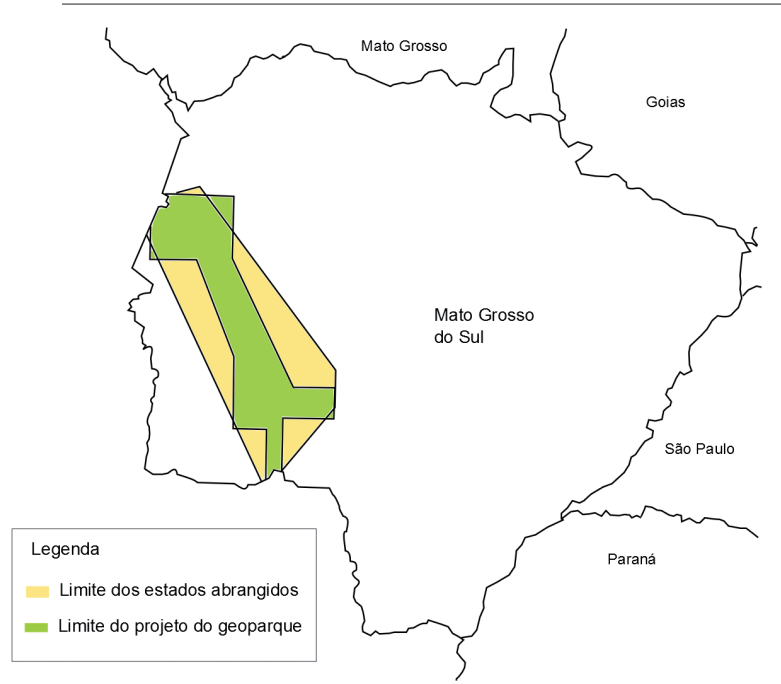

Figura 3. Mapa esquemático do território destinado à criação do Geoparque "Bodoquena-Pantanal" em relação ao centro-oeste brasileiro. Desenho de Priscila Valentin (Modif. de Geoparque Bodoquena-Pantanal 2010)

escolar (gestores, diretores, docentes e funcionários) sobre as imediações e importância da proteção do território (Vilas-Boas 2012, Silveira et al. 2012, Vilas-Boas 2012).

na região estrutura-se o desenvolvimento econômico de maneira indireta ou diretamente ligado ao geoparque, como a formação de cursos técnicos de guias turísticos e a estratégia de venda de artesanato e gastronomia como geoprodutos (Silveira et al. 2012, Vilas-Boas 2012).

Apesar dos benefícios, o geoparque apresenta atualmente problemas como a falta de expansão educativa e o recorrente tráfico de fósseis (Alves et al. 2011, Silveira et al. 2012, Vilas-Boas 2012). Fósseis excepcionalmente preservados têm grande apelo ornamental e são facilmente reconhecidos, chamando muita atenção de populares, turistas e contrabandistas, que obtêm, pelo tráfico, recursos financeiros (Silveira et al. 2011, Vilas-Boas 2012).

Concomitante às atividades de tráfico, a falta de desenvolvimento regional é um problema recorrente, havendo um processo de favelização com aumento populacional irregular em áreas, que avançam anualmente na localidade do Geotope Granito (grande potencial para pesquisas com relação ao embasamento cristalino global) (Alves et al. 2011).

Em suma, a grande extensão do Geoparque do Araripe, uma trabalhosa estratégia educativa que atinja todos os envolvidos e dificuldades de fiscalização do tráfico do patrimônio fossilífero pelo DNPM e IPHAN, acarretam os principais problemas no território do Araripe (Alves et al. 2011, Silveira et al. 2012, Vilas-Boas 2012).
O tráfico de fósseis e a falta de engajamento da população com o geoparque estão intimamente relacionados com a ineficácia da prática educativa. Medidas de divulgação científica podem auxiliar a compreensão do conceito de geoparque por populares, acarretando no desenvolvimento da região e preservação dos recursos e patrimônios naturais (Silveira et al. 2012, Vilas-Boas 2012).

Ainda com todos os problemas listado, ele permanece ligado a Rede Global de Geoparques da UNESCO (Silveira et al. 2012, Vilas-Boas 2012). Algumas deficiências persistem, porém, apresenta mais da metade de seu território gerenciada de forma eficaz (cerca de 60,9\%) (Silveira et al. 2012).

\section{Análise da área candidata: 0 caso do Geoparque Bodoquena-Pantanal}

O candidato a geoparque Bodoquena-Pantanal se localiza no Centro-Oeste do Brasil, predominantemente no Estado de Mato Grosso do Sul, abrangendo as microrregiões de Bodoquena, Alto Pantanal e Aquidauana (Fig. 3), atingindo parcialmente os municípios de Porto Murtinho, Ladário, Nioaque, Jardim, Bonito, Bela Vista, Guia Lopes da Laguna, Caracol, Corumbá, Miranda e Bodoquena. Sua área física corresponde a aproximadamente $20.000 \mathrm{Km}^{2}$ com 54 geossítios que incluem pedreiras, grutas, cachoeiras, nascentes, monumentos, baías e minas (Geopark Bodoquena-Pantanal 2010, Geopark Bodoquena-Pantanal 2013).

A região representa um choque de extremos biogeográficos e temporais, do Pré-Cambriano ao Quaternário. Um verdadeiro depósito fossilífero de microbialitos e dos primeiros metazoários da América do Sul, evidenciados nos grupos Jacadigo $(1730 \pm 22 \mathrm{Ma} / 889 \pm 44 \mathrm{Ma}$ até $623 \pm 15 \mathrm{Ma})$ (Hasui and Almeida 1970; O'Connor and Walde, 1985; Freitas et al. 2011; Piacentini et al. 2013) e Corumbá (ca $543 \mathrm{Ma}$ ) (Fairchild et al. 2012, Soares et al 2013, Kerber et al. 2013, Morais 2013), que contrasta com os registros paleontológicos de pegadas dinossauriformes da Formação Botucatu e da megafauna pleistocênica das regiões cársticas da Serra da Bodoquena (Scheffler et al. 2010, Oliveira 2013). Além disso, conta com cerca de 417 sítios arqueológicos de caçadores-coletores e índios ceramistas (Martins 1992, Oliveira e Viana 2000, Schimitz 1998), cadastrados pelo IPHAN.

A área candidata é atualmente administrada pela entidade "Geoparque Estadual Bodoquena-Pantanal”. Apesar do nome, a área não se integra 
ao GGN da UNESCO (Geopark Bodoquena-Pantanal 2010). Porém, a entidade coopera para a consolidação do selo e junto a vinculação com a GGN.

Com esse intuito, em outubro de 2010, o comitê do Geoparque Estadual Bodoquena-Pantanal apresentou à UNESCO um dossiê completo com dados sobre características geográficas, culturais, geológicas, paleontológicas, e de biodiversidade, dentre outros.

Apesar dos esforços para a integração do território na GGN, em meados de 2012, o auspício da UNESCO foi negado. Um problema identificado na área candidata, em especial nas proximidades de Corumbá, foi a falta de divulgação para a comunidade sobre o conceito e a funcionalidade de um geoparque. As entrevistas realizadas no Ecoparque da Cacimba corroboram a afirmação, demonstrando que a população imersa no contexto desconhece o real significado de um geoparque.

A falta de ações efetivas de EA e da EP acarreta na falta de conhecimento da comunidade sobre as temáticas que a cerca fósseis, desenvolvimento sustentável, geoconservação e, até mesmo, pesquisas científicas. Tal problemática colide com os pressupostos básicos para o estabelecimento e o funcionamento de um geoparque.

Fica explícita para a localidade a falta de intercâmbio entre o conhecimento científico e o público leigo. Muitas pessoas da comunidade observam a movimentação de pesquisadores, porém não entendem as razões de tal e/ou muito menos se questionam sobre isso. Essa tendência se agrava a partir do momento em que habitantes vizinhos aos afloramentos desconhecem a existência de grupos fósseis ocorrentes, afirmando, muitas vezes, que tais organismos até "circulam nas localidades", confundindo-os com animais modernos (ou míti$\cos$ ?) da região.

Todas essas problemáticas podem estar relacionadas aos caráter ainda recente dos esforços em Geoconservação e proteção do patrimônio geológico. Os métodos e pressupostos das ações geoconservacionistas foram formalizadas somente no final do século XX (Gray 2004, Brockx e Semeniuk 2007) e originários em contextos europeus, completamente diferentes da realidade brasileira (Zouros 2004).

Ocorre, portanto, no Brasil, a falta de conhecimento da estruturação de métodos eficazes para se atingir a geoconservação (devido à natureza recente desses esforços em nosso país). Fato que consiste na base para o desenvolvimento de EA e EP, assim como, para a divulgação e diálogo científico com a comunidade.

Apesar de todos os problemas relatados, a área possui um grande potencial para pesquisas, divulgação, educação e desenvolvimento sustentável, estruturado em ricos registros geológicos e arqueológicos, além de uma extrema necessidade de conservação da diversidade biológica e geoconservação. Todavia, torna-se salutar que medidas efetivas sejam tomadas para a estruturação e inter-relação dos pilares: educação, ciência e desenvolvimento sustentável nesta região.

\section{Estratégias de divulgação}

Uma medida eficaz para mitigar as questões apontadas seria a criação de esforços educativos voltadas para a comunidade, contemplando questões como o registro fossilífero e arqueológico local, a sua importância regional e mundial, a proposta do geoparque, os benefícios do mesmo para a população, como auxiliar na manutenção e, por fim, como esses aspectos podem modificar os panoramas vivenciados pela população.

Uma alternativa para se contornar esse problema seria a implementação de palestras, aulas, minicursos e o reforço dos mesmos com material didático, como cartazes informativos (Fig. 4) e histórias em quadrinhos (Figs. 5 e 6) para a divulgação. De forma lúdica, esses materiais podem estimular e promover a disseminação de conhecimento entre os mais variados públicos da região, desde moradores tradicionais, a turistas e, até mesmo, projetar nacional e internacionalmente a região, em decorrência da existência do fóssil símbolo do Ediacara-

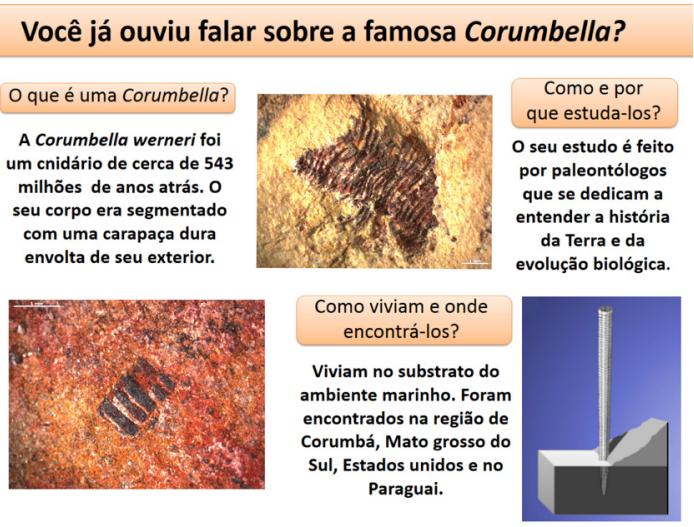

Figura 4. Cartaz informativo com informações paleobiológicas sobre o metazuário Corumbella werneri, cnidarea, scyphozoa 


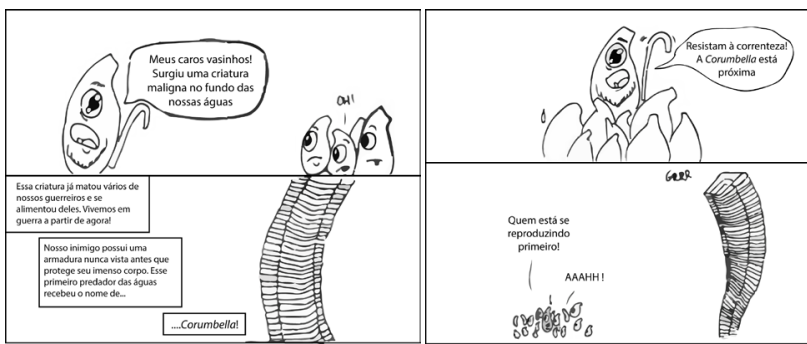

Figura 5. Material de divulgação e ensino (história em quadrinhos), contendo informações paleoecológicas sobre os fósseis encontrados no período Ediacarano em Corumbá, MS. Ênfase para os Vase Shaped Microfossils (VSMs) e Corumbella werneri. A história acompanha um texto de apoio para professores e alunos (Texto de apoio 1)

no no Brasil, a Corumbella, e do grande potencial para novas descobertas sobre o Quaternário, com a megafauna do Pleistoceno, e suas possíveis relações com seres humanos, no passado.

As atividades podem, também, abarcar o público das instituições de Ensino Superior das regiões de entorno, a fim de promover uma maior aproximação das universidades com o contexto do geoparque e até estimular atividades socioeducativas por meio de projetos de extensão que podem ser realizados com o apoio dos próprios estudantes dos cursos superiores.

A utilização de histórias em quadrinhos com estas temáticas, possibilitam a disseminação eficaz e informativa sob o pretexto de personagens carismáticos, despertando assim o interesse do público-alvo envolvido, ao mesmo tempo que transmite conteúdos específicos, (Figs. 5 e 6), os quais, se direcionados conforme os textos de apoio (Figs. 7 e 8), proporcionariam grandes avanços no processo de ensino e aprendizagem.

\section{Texto de apoio 1: Mato Grosso do sul e 0 alvorecer da vida animal}

\section{Explorando o tempo e a evolução da vida}

O Pré-Cambriano é um longo intervalo de tempo ${ }^{1}$, que os geólogos denominam "éon", que corresponde à fase anterior de seu seguinte éon: o Fanerozoico (que quer dizer "vida visível"), quando a vida se estabeleceu de modo abundante e diverso. O Pré-Cambriano compreendeu a fase mais longa da história evolutiva da vida na Terra. A maioria dos cientistas concordam que o registro fóssil mais antigo de

\footnotetext{
1 Para maiores informações sobre a escala de tempo geológico, consulte: International Chronostatigraphic Chart v2015/01 (Cohen et al. 2013) em: www.statigraphy.org
}

vida na Terra data de aproximadamente 3,5 bilhões de anos no éon Arqueano. A vida, durante a maior parte desse "éon", foi dominada por microrganismos (principalmente cianobactérias) que, de acordo com alguns biólogos, evoluíram de forma espantosamente lenta.

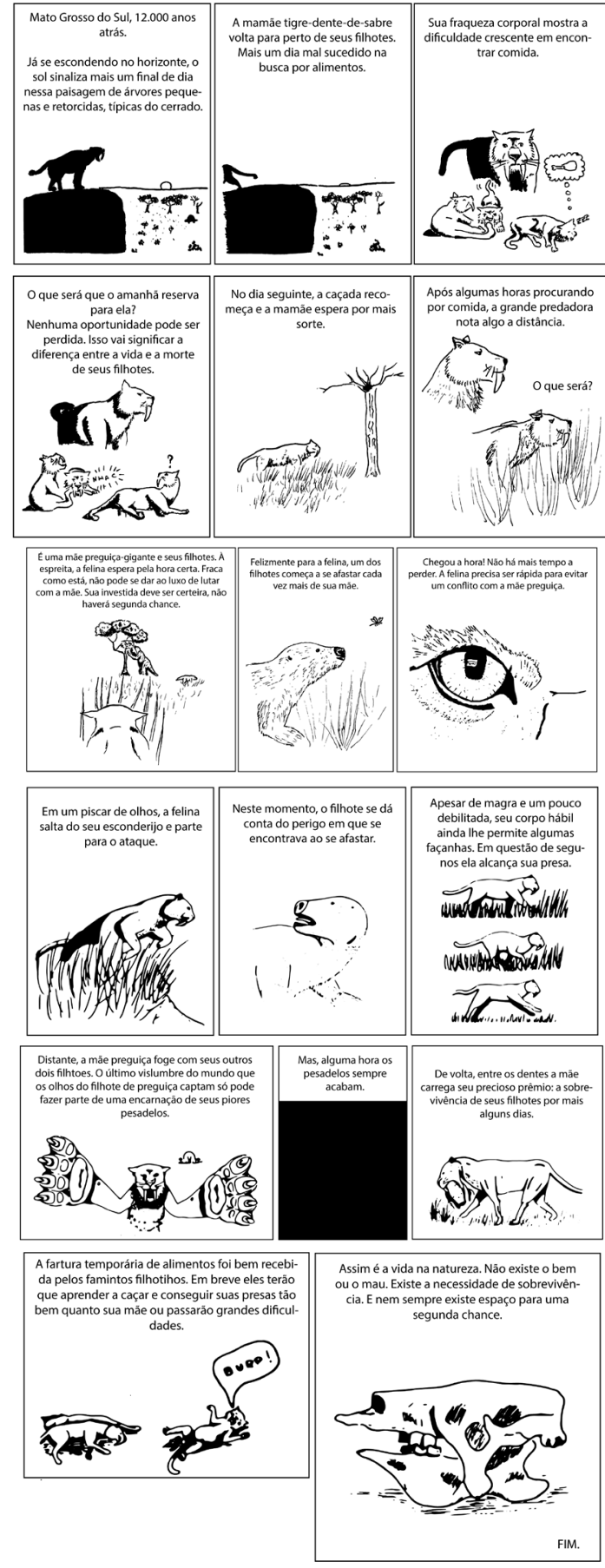

Figura 6. Material de divulgação (história em quadrinhos), com informações paleontológicas, sobre fósseis representantes da megafauna do Pleistoceno na Bodoquena, MS (Período Quaternário). A história acompanha um texto de apoio para professores e alunos (Texto de apoio 2) 


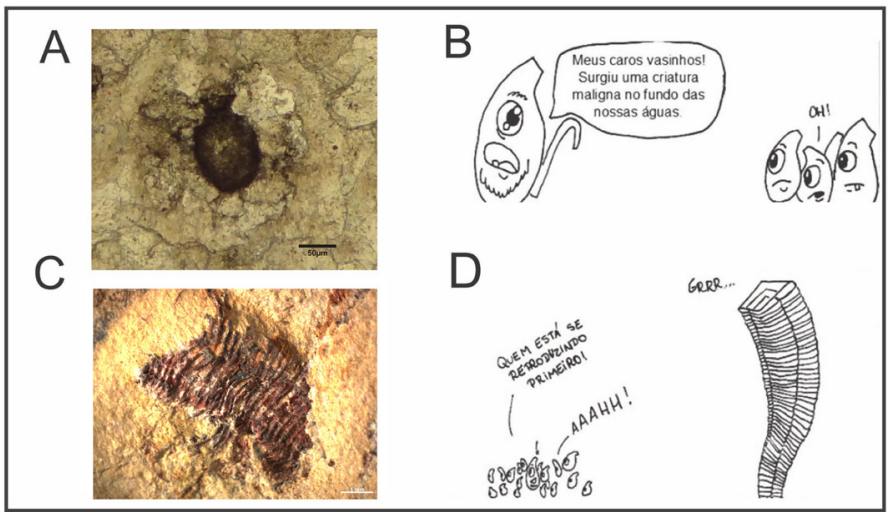

Figura 7. Explorando o quadrinho "Quando os animais dominaram o planeta...". Explicações (A): Vase Shaped Microfossil ("vasinho") da Formação Urucum, Grupo Jacadigo (B) ilustrações dos VSMs ("vasinhos"); (C) Fóssil de Corumbella encontrado em Corumbá, MS; (D) ilustração e reconstituição de Corumbella. Fontes: Zaine, 1991, Pacheco, 2012. Escalas: A) $50 \mu \mathrm{m}$; c) $1 \mathrm{~mm}$

Por outro lado, ainda no Pré-Cambriano, a era Neoproterozoica (datada entre 1 bilhão e 542 milhões de anos) foi caracterizada como uma fase geológica de dramáticas mudanças biológicas e ambientais, e importantes inovações evolutivas. Repetidas glaciações (também conhecidas como "eras do gelo") de extraordinária magnitude, inclusive global, e grandes eventos de liberação de nutrientes nos oceanos foram relatados para este intervalo de tempo. É provável que neste contexto de pressões ambientais e de oferta de nutrientes, tenham surgido e se diversificado vários seres unicelulares de maior complexidade que, eventualmente, evoluíram à multicelularidade, tornando-se mais abundantes ao final desta era.

Apenas no final do último período do Neoproterozoico, denominado Ediacarano (entre 630 e 542 milhões de anos), surgiu, no registro fóssil, um conjunto de organismos macroscópicos complexos que compuseram a biota de Ediacara, assim denominada por ter sido originalmente encontrada nas colinas de Ediacara, Austrália. Na estranha biota, em seus primeiros momentos evolutivos, muitos organismos não tinham partes resistentes (duras), tais como conchas ou esqueletos, sendo, em alguns casos, caracterizada como criaturas de corpo mole, atribuídos a um extinto grupo de seres unicelulares gigantes: os Vendobionta. Estes também são denominados "organismos acolchoados", por serem ocos e terem a forma de colchões de ar ou lembrarem pneus.

Os organismos da biota de Ediacara apresentam registro em, pelo menos, 40 localidades, no mundo, variando entre 580 e 541 milhões de anos e contemplam desde seres de corpo mole (mais antigos) até os primeiros animais capazes de secretar esqueletos (mais recentes).

\section{O dilema de Darwin}

O aparecimento repentino de fósseis de organismos complexos em níveis cambrianos (hoje datados entre 542 e 488 milhões de anos), já havia sido notado por Charles Darwin. Isso o assombrava, pois, desde então, a Teoria da Evolução explicava a transformação das espécies apenas de forma suave, contínua e gradual, ao longo do tempo geológico. O quase misterioso e súbito aparecimento desses complexos organismos sem precedentes no registro fossilífero, ricos em formas e interações ecológicas ( $p$. ex. predadores e parasitas), tornou-se um dilema que "tirou o sono" de Darwin, balançando os alicerces da Evolução da vida no planeta. É como se essa grande variedade de formas de vida tivesse surgido "do nada" e Darwin não tinha explicação para tal fato. Infelizmente, Darwin morreu sem resolver seu dilema.

Em uma analogia entre as 24 horas de um dia terrestre e o tempo geológico, desde a origem do planeta, no Hadeano (Pré-Cambriano) (há cerca de 4,5 bilhões de anos) até o aparecimento abundante das primeiras formas de vida visível e complexa (há

A

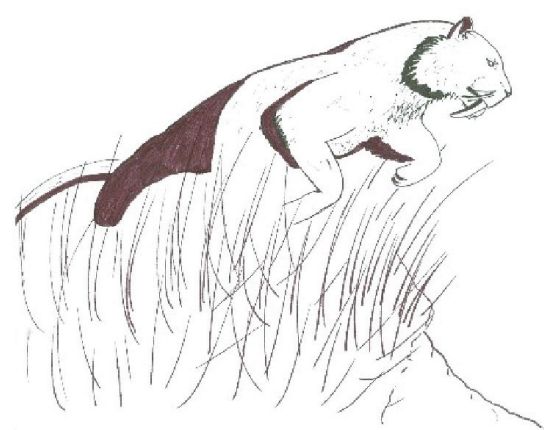

B

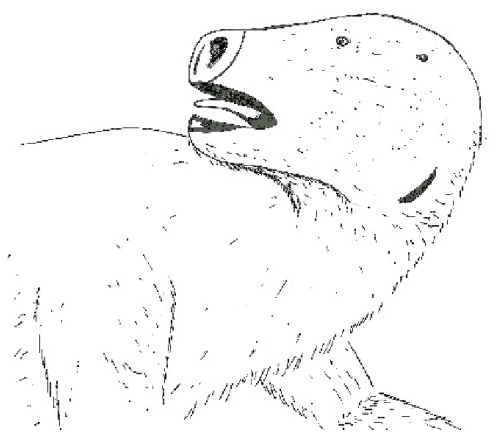

Figura 8: Explorando o quadrinho "Gigantes de um passado não muito distante": (A)Representação lúdica de um tigre-dente-de-sabre; (B) Representação lúdica de um filhote de preguiça gigante. Esses peculiares animais viveram na época pleistocênica. 
cerca de 580 milhões de anos), teriam se passado aproximadamente 20 horas e mais alguns minutos, até o aparente repentino surgimento dos invertebrados, em um evento denominado "Explosão Cambriana da Vida” (há aproximadamente 540 milhões de anos).

No Brasil, sob um calor escaldante de 41 graus, em minas de calcário localizadas em Corumbá e Ladário, cidades onde o Pantanal encanta por sua exuberância, cientistas brasileiros e alemães descreveram, na década de 1980, um dos animais que viveu, em nossa analogia entre o dia terrestre e o tempo geológico, alguns segundos antes da “explosão" Cambriana. Corumbella (Figs. 7C, D), datada em cerca de 543 milhões de anos, foi um dos animais que compôs o último momento evolutivo da biota de Ediacara, no limite Ediacarano/ Cambriano, quando os animais estavam saindo da sombra de outros seres e florescendo em suas mais diversas formas e interações ecológicas.

Até o momento, podemos seguramente afirmar que Corumbella foi um animal pertencente ao grupo dos cnidários (que atualmente inclui as águas vivas), que viviam fixos ao substrato. Em nossa recente reconstituição de Corumbella, descobrimos mais uma característica que as aproxima ainda mais dos animais do final do Ediacarano: elas são portadoras de uma carapaça relativamente espessa e resistente, além de abertura oral, inovações que a tornava um dos mais fantásticos predadores dos mares Ediacaranos.

Também na região de Corumbá, em uma unidade geológica mais antiga e abaixo da formação da qual são encontrados os fósseis de Corumbella, foram encontrados microfósseis em formas de vaso (conhecidos em inglês como Vase-Shaped Microfossils - VSMs). Os microfósseis foram formados por organismos unicelulares (ou seja, que possuíam uma célula apenas) e que tinham uma carapaça (chamada tecnicamente de teca) que curiosamente tinha o formato de um pequeno vaso. Nas rochas em que se encontram os VSMs, não há registro de organismos multicelulares (ou seja, constituídos por mais de uma célula). Seres multicelulares aparecem depois no registro geológico da região de Corumbá, sendo pertencentes aos primeiros animais capazes de construir um esqueleto de verdade, como a Corumbella.

Além da relevância científica de Corumbella e dos microfósseis em forma de vaso para a Paleontologia mundial, a ocorrência deste enigmático fóssil Ediacarano, na região de Corumbá, apresenta implicações para o desenvolvimento de estratégias de geotourismo, no Brasil. A presença de tão importante e remoto fóssil, em um cenário de choque de extremos temporais, revelado pela presença do recente domínio biogeográfico do Pantanal (formado ainda na nossa atual Era Cenozoica) e das mais pregressas formações geológicas Pré-Cambrianas, em Mato Grosso do Sul, podem viabilizar que o então Geoparque Bodoquena/ Pantanal venha a se tornar o segundo das Américas (atrás apenas de outro geoparque brasileiro, o Geoparque do Araripe) e o $58^{\circ}$ na Cadeia Mundial de Geoparques aprovada pela UNESCO.

\section{Texto de apoio 2: Os segredos das cavernas}

Leões, elefantes, girafas e rinocerontes. Provavelmente você já ouviu falar um pouco sobre esses grandes animais. Atualmente, com algumas exceções, são grandes mamíferos apenas encontrados no continente africano. Mas o que pouca gente sabe é que nem sempre foi assim.

Em um passado não muito distante, mamíferos e aves de gigantes eram muito mais comuns do que hoje em dia. Mamutes e mastodontes andavam em bandos nas pradarias; tigres-dente-de-sabre caçavam suas presas com seus longos caninos; e gliptodontes, parentes dos atuais tatus e que podiam chegar ao tamanho de um fusca, se protegiam-se com suas espessas e rígidas carapaças. Esses são pequenos (ou grandes) exemplos de como era a vida no Pleistoceno. A Época, que durou de 2.59 milhões de anos até aproximadamente 11.000 anos atrás, é a primeira do Período Quaternário da Era Cenozoica, seguida pela Época atual, o Holoceno.

No Brasil, são várias as ocorrências de fósseis de grandes animais (coletivamente chamados de megafauna) do Quaternário. Muitos destes restos fossilizados são encontrados em cavernas, fundo de lagoas e até mesmo em drenagens de rios. As cavernas da Serra da Bodoquena (Mato Grosso do Sul), por exemplo, possuem diversos fósseis pertencentes à megafauna, assim como de pequenos animais. $\mathrm{O}$ ambiente dentro da caverna é propício à preservação de restos esqueléticos. A água ligeiramente ácida que dissolve as rochas carbonáticas e produz cavernas e túneis em meio a rocha, também causa a incrustação de minerais em restos orgânicos, como os ossos de animais. É dessa forma, que estes restos conseguem perdurar por mais tempo sem serem degradados. Quando 
os paleontólogos encontram esses fósseis, eles identificam a quais tipos de animais eles pertenceram e, assim, conseguem compreender um pouco sobre a fauna de uma determinada época. Um dos grandes desafios atualmente nos estudos sobre o Quaternário é tentar entender porque a megafauna foi extinta em diversas partes do globo mais ou menos ao mesmo tempo (aprox. 11.000 anos atrás). Esta extinção ainda é um tema muito controverso entre os cientistas. Apesar de não se saber ao certo a sua causa, duas hipóteses são as mais prováveis: [1] extinção causada por mudanças climáticas, ou, [2] extinção causada pela caça excessiva realizada pelas populações humanas pretéritas. Uma maneira de procurar por evidências de predação por humanos é identificar a presença de marcas nos fósseis que poderiam ter sido causadas por instrumentos lapidados em rochas. Ainda não existem vestígios concretos desse tipo de interação - predação da megafauna por humanos - aqui na América do Sul. A ausência de marcas de predação é ainda mais impressionante caso as primeiras populações brasileiras humanas da América do Sul tenham chegado bem antes do que se pensava, como tem mostrado algumas evidências. Será que as primeiras populações não caçavam animais da megafauna? Se não caçavam ou caçavam muito pouco, qual foi o motivo da extinção da megafauna? Como esses grandes animais viviam, o que eles comiam e como eles interagiam uns com os outros? Muitas perguntas ainda precisam de respostas, e há uma boa perspectiva para o avanço desta área da Paleontologia. Um motivo para este otimismo é a assombrosa quantidade de informação disponível, e as que ainda podem vir a ser descobertas. No Estado de Mato Grosso do Sul, por exemplo, há a estimativa de existirem centenas de cavernas. Atualmente, apenas cerca de cinco dessas cavernas foram estudadas do ponto de vista paleontológico. E muito ainda precisa ser feito só nas cavernas já estudadas. Com o avanço das pesquisas, muitas das perguntas serão resolvidas e, provavelmente, muita dessa informação será retirada dos depósitos quaternários sul-mato-grossenses.

\section{Um breve relato sobre os mamíferos e 0 Cenozoico}

Por incrível que pareça, a história dos mamíferos é muito mais antiga do que apenas o Quaternário. Este grupo provavelmente surgiu no final do Triássico (aprox. 220-230 milhões de anos), o primeiro período do Mesozoico. Durante o tempo dos grandes dinossauros, os mamíferos, em sua grande maioria, eram insetívoros e de pequeno porte. No final do Mesozoico, há 65 milhões de anos, os dinossauros não avianos foram extintos (como as aves evoluíram dos dinossauros, elas tecnicamente são dinossauros) juntamente com vários outros grupos de animais terrestres e marinhos. A razão desta extinção ainda não foi completamente elucidada; uma das explicações envolve o provável impacto de enorme meteorito na Terra. Após a extinção dos dinossauros não avianos, os mamíferos se diversificaram rapidamente no início do Cenozoico, atingindo formas e tamanhos jamais vistos. É por conta disso que a Era Cenozoica é geralmente chamada de a "Idade dos Mamíferos". O Cenozoico é dividido em três Períodos: Paleogeno, Neogeno e Quaternário. É no Paleogeno que ocorre a grande diversificação dos mamíferos, mas não foram apenas eles que se diversificaram bastante. Outros grupos, como, por exemplo, as aves, também sofreram grande irradiação de formas e espécies. Já no Neogeno a fauna começa a ficar mais parecida com a moderna. Os primeiros hominídeos surgem, as gramíneas se diversificam muito, propiciando o surgimento de vários mamíferos pastadores, e ocorre a formação do ístmo do Panamá, que fez a ligação continental entre a América do Sul e a América do Norte e permitiu grande intercâmbio de fauna entre as duas regiões. O já mencionado Quaternário, o último Período, é marcado pelo surgimento dos humanos modernos (Homo sapiens), por uma série de glaciações que culminaram no Último Máximo Glacial e pela extinção de grandes animais terrestres (a megafauna).

\section{Considerações Finais}

Os geoparques compõem uma iniciativa de conservação e desenvolvimento científico, social e educacional de uma região de apelo cênico e natural. Contudo, para sua implementação, faz-se necessário o estabelecimento de uma equipe interdisciplinar de planejamento e o apoio das autoridades competentes. O Geoparque Arouca é considerado um modelo ideal para estruturação de geoparques na Europa, cumprindo todas as diretrizes da UNESCO; atua nos campos educativo, social e de conservação.

No território brasileiro, o Geoparque Araripe se destaca por ser o único das Américas com 
grande potencial de desenvolvimento e uma boa equipe de manejo. Tem que lidar com problemas relacionados ao tráfico de fósseis e processos de favelização. Porém, diversos profissionais atuam de forma a mitigar esses aspectos. Com o passar do tempo, se forem cumpridas as propostas de manejo para o aprimoramento, pode vir a se tornar um modelo no Brasil.

A área candidata "Geoparque Bodoquena-Pantanal" apresenta um rico registro fossilífero, com patrimônio cultural e arqueológico inserido em um contexto de grande beleza cênica, no Pantanal e Cerrado Sul-Mato-Grossense, caracterizando-se como área prioritária para a incorporação ao GGN da UNESCO. Contudo, apresenta problemas de manejo, por ser uma área extremamente grande e com o baixo envolvimento do contexto e da proposta de geoparque com as comunidades locais. Sendo assim, possíveis soluções para transformação e resolução parcial dos problemas se encontram no investimento em ações sociais e educativas de curto e longo prazo, assim como o desenvolvimento de uma proposta de redução de área do geoparque, possibilitando maior viabilidade de gestão.

\section{Agradecimentos}

Agradecemos ao consultores Dr. Caue N. De Oliveira, Dr. Celso Dal Ré Carneiro pela revisão e sugestões de aprimoramento do manuscrito, Dr. Paulo César Boggiani pelo auxílio e disponibilidade de informações relevantes ao longo da pesquisa, a Msc. Luana P. C. de Morais, Msc. Guilherme Raffaeli Romero e Msc. Alessandro Marques de Oliveira pelas sugestões sobre o manuscrito.

\section{Referências}

Alves R.M., Duarte F.R., Miranda J.G.V. 2011. Geoparque Araripe e o Museu de Paleontologia de Santana um estudo preliminar dos aspectos comunicacionais relacionados à difusão do conhecimento. In: Congr. Bras. Bibliot., Doc. Ciênc. Inf.: Sistemas de informação, multiculturalidade e inclusão social. Maceió, Alagoas. URL: http://febab.org.br/XXIV_CBBD/wp-content/ uploads/2011/07/trabalhos_orais.pdf. Acesso 13.10.2013.

Babcock L.E., Grunow A.M., Sadowski G.R., Leslie S.A. 2005. Corumbella, an Ediacaran-grade organism from the Late Neoproterozoic of Brazil. Palaeogeography, Palaeoclimatology, Palaeoecology, 220(1): 7-18.
Bacci D.L., Piranha J.M., Boggiani P.C., Lama E.A.D., Teixeira W. 2009. Geoparque. Estratégia de Geoconservação e Projetos Educacionais. Geol. USP, Publ. Esp, 5: 7-15.

Boggiani P.C. 2010a. A experiência do Geopark Arouca para MS. In: Portal Bonito o portal do paraíso. URL: http://www.portalbonito.com.br/colunistas/paulo-boggiani/359/a-experiencia-do-geopark-arouca-para-ms. Acesso 08.07.2013.

Boggiani P.C. 2010b. Geoparques não tratam só de pedras. In: Portal Bonito o portal do paraíso. URL: <http://www.portalbonito.com.br/colunistas/paulo-boggiani/358/geoparque-nao-trata-so-de-pedras. Acesso 08.07.2013.

Boggiani P.C. 2010c. Geoparque da Bodoquena e Pantanal/UNESCO. In: Portal Bonito o portal do paraíso.URL:<http://www.portalbonito.com.br/colunistas/paulo-boggiani/357/geoparque-da-bodoquena-e-pantanal-unesco > Acesso 08.07.2013.

Brasil. DNPM, CPRM e SIGEP. 2002. Sítios Geológicos e Paleontológicos do Brasil. Editores: Schobbenhaus C., Campos D. A., Queiroz E. T., Winge M., Berbert-Born M. L. C. Brasília. 554 p.

Brilha J.B.R. 2009. A Importância dos Geoparques no Ensino e Divulgação das Geociências. Geol. USP, Publ. Esp, 5:27-33.

Brilha J.B.R., Carvalho A.M.G. 2010. Geoconservation in Portugal: an introduction. Org. Neiva J.M.C., Ribeiro A., Victor M., Noronha F., Ramalho M. In: Ciências Geológicas: Ensino, Investigação e sua História II, Publicação Comemorativa do "Ano internacional do Planeta Terra", 2:435-441.

Brockx M. and Semeniuk V. 2007. Geoheritage and geoconservation- history, definition, scope and scale. J. R. Soc. West. Aust. 90(2): 53-87.

Christiansen P. 2012. The making of a monster: postnatal ontogenetic changes in craniomandibular shape in the great sabercat Smilodon. PLoS ONE. 7(1):1-11.

Cohen K.M., Finney S.C., Gibbard P.L. \& Fan J.-X. (2013; updated). The ICS International Chronostratigraphic Chart. Episodes, 36:199-204.

Duarte F.R., Miranda J.G.V. 2011. O Geoparque Araripe como pólo difusor do conhecimento no semiárido nordestino. Perpectivas em gestão e conhecimento, 1(2):249-265.

Eder F.W., Patzak M. 2004. Geoparks—geological attractions: A tool for public education, recreation and sustainable economic development. Episodes, 27:162-164.

Fairchild T.R., Sanchez E.A.M., Pacheco M.L.A.F., Leme J.M. 2012. Evolution of precambrian life in the Brazilian geological record. Int. J. Astrobio$\log \gamma$, 11(4):309-323.

Freitas B.T., Warren L.V., Boggiani P.C., Almeida R.P., Piacentini T. 2011. Tectono-sedimentary evolution of the Neoproterozoic BIF-bearing 
Jacadigo Group, SW-Brazil. Sedimentary Geology, 238:48-70.

Geopark Araripe 2013. O Geopark Araripe. URL: <http://geoparkararipe.org.br/?page_id=266> Acesso 12.10.2013.

Geopark Arouca 2013. O Geoparque Arouca. URL: $<$ http://www.geoparquearouca.com/?p=geoparq ue\&sp = ogeoparquearouca $>$ Acesso 15.09.2013.

Geopark Bodoquena Pantanal. Geopark Bodoquena-Pantanal. URL: < http://www.geoparkbodoquenapantanal.ms.gov.br/> Acesso 20.08.2013.

Geopark Bodoquena Pantanal 2010. Geopark Bodoquena-Pantanal: o alvorecer da biodiversidade, dossiê de candidadtura à rede global de geoparksnacinais sob auspício da organização das Nações Unidas para a educaçã, ciência e cultura/UNESCO. IPHAN/MS URL: < http://www.geoparkbodoquenapantanal.ms.gov.br/> Acesso 20.08.2013.

Gray M. 2004. Geodiversity - valuing and conserving abiotic nature. John Wiley and Sons, Chichester, United Kingdom.

Gutiérrez-Marco J.C., Sá A.A., García-Bellido D.C., Rábano I.; Valério M. 2009. Giant trilobites and trilobite clusters from the Ordovician of Portugal. Geology, 37:443-446.

Hahn G., Hahn R., Leonardos O.H., Pflug H.D. \& Walde D.H.G. 1982. Kfrperlich Erhaltene Scyphozoen-Reste aus dem Jungprekambrium Brasiliens. Geol. Palaeontol, 16:1 -18.

Hasui Y., Almeida F.F.M. 1970. Geocronologia do Centro-Oeste brasileiro. B. Soc. Bras. Geol, 19(1):5-26.

Kerber B.B., Rosa A.L.Z., Gabas S.G., Leme J.M., Pacheco M.L.A.F. 2013. O registro fossilífero de metazoários ediacaranos na América do Sul e suas implicações nos estudos sobre origem e complexificação da vida animal. Geol. USP, Sér. cient., 13:51-64.

Martinelli A.G., Ferraz P.F., Cunha G.C., Cunha I.C., Carvalho I.S., Ribeiro L.C.B., Neto F.M., Cavellani C.L., Teixeira V.P.A., Ferraz M.L.F. 2012. First record of Eremotherium laurillardi (Lund, 1842) (Mammalia, Xenarthra, Megatheriidae) in the Quaternary of Uberaba, Triângulo Mineiro (Minas Gerais State), Brazil. J South Am Earth Sci., 37:202-207.

Martins G. R. 1990. Relatório de registro do Sítio Paleontológico "MS-NI-01". Revista Científica, 5(1):7-12.

Martins G. R. 1992. Breve Painel Etno-Histórico de Mato Grosso do Sul. In: Campo Grande/MS: Edufms, 1992. 1-75.

McKeever P.J., Zouros N. 2005. Geoparks: Celebrating Earth heritage, sustaining local communities. Episodes: Journal of International Geoscience, 28(4):274-278.

McKeever P.J., Zouros N., Patzak M. 2010. The
UNESCO Global Network of National Geoparks. The George Wright Forum - The journal of parks, protected areas, and cultural sites, 21(1):14-18.

Morais L.P.C. 2013. Paleobiologia da formação Bocaina (Grupo Corumbá), Ediacarano, Mato Grosso do Sul. Inst. Geoc. USP. 132p. (Dissert. de Mestrado).

Morais L.P.C.S., Kerber B.B., Osés G.L., Oliveira A.M., Pacheco M.L.A.F. 2013. Paleobiologia e Evolução: o potencial do registro fossilífero brasileiro. Revista Espinhaço, 2(1):24-40.

O'Connor E.A., Walde D.H.G., 1985. Recognition of an Eocambrian Orogenic Cycle in SW Brazil and SE Bolivia. Zentralblatt für Geologie und Paläontologie, 9(10):1441-1456.

Oliveira A.M. 2013. Paleofauna de vertebrados, com ênfase em répteis e mamíferos, dos depósitos quaternários da região da Serra Bodoquena, Mato Grosso do Sul, Brasil. Rio Claro, São Paulo. Inst. Geoc. e ciências Exatas. UNESP. 141p. (Dissert. Mestrado).

Pacheco M.L.A.F., Leme J., Machado A. 2011. Taphonomic Analysis and Geometric Modelling for the Reconstitution of the Ediacaran Metazoan Corumbella werneri Hahn et al. 1982(Tamengo Formation, Corumbá Basin, Brazil). Journal of Taphonomy, 9(4): 269-283. Abril 2012.

Piacentini T., Vasconcelos P.M., Farley K.A. 2013. ${ }^{40} \mathrm{Ar} /{ }^{39} \mathrm{Ar}$ constraints on the age and thermal history of the Urucum Neoproterozoic banded iron-formation, Brazil. Precambrian Research, 228:48-62.

Piranha J. M., Lama E. A. D. 2011. Geoparks in Brazil. Strategy of Geoconservation and Development. Geoheritage, 3(4):289-298.

Ribeiro L. C. B., Carvalho I. S., Schobbenhaus C., Paula V., Teixeira A., Trevisol A., Martins A., Neto F.M., Ferraz M.L.F. 2011. Geoparque Uberaba - Terra dos Dinossauros do Brasil. I Simposio de Geoparques y Geoturismo en Chile.

Rocha D., Brilha J., Sá A. A. A. 2008. Inventariação e a avaliação do património geológico na fundamentação científica do Geoparque Arouca (norte de Portugal). Memórias e Notícias - Publicação do Departamento Ciências Terra e do Museu Mineralogia e Geologia da Universidade de Coimbra, 3.

Rocha D., Paz A., Sá A.A., Duarte A.C. 2011. Programas Educativos do Geoparque Arouca: contributos para uma Educação para o Desenvolvimento Sustentável. XVIII Jornadas pedagógicas de educação ambiental para a sustentabilidade.

Rocha-Campos A. C. 2002. Varvito de Itu, sp Registro clássico da glaciação neopaleozóica. Sítios paleontológicos e geológicos do Brasil (Sigep), 62:147-154.

Rolim F.G., Theodorovicz A. 2010. Geopark Bodoquena-Pantanal o alvorecer da biodiversidade. Dossie de candidatura à rede global de geoparques nacionais sob aupício da organização das nações unidas para educação, ciências e cultura/ UNES- 
CO. URL:<http://www.cprm.gov.br/publique/ media/dossie_bodoquena_portugues_unesco. pdf $>$ Acesso 15.09.2013.

Sá A.A., Brilha J., Cachão M., Couto H., Medina J., Rocha D., Valério M., Rábano I., Guitiérrez-Marco J.C. 2006a. Geoparque Arouca: um novo projecto para o desenvolvimento sustentado baseado na conservação e promoção do Património Geológico. In: Mirão, J. \& Balbino A. (coords.). Livro de resumos do VII Congresso Nacional de Geologia, Universidade de Évora, Estremoz.

Sá A.A., Santos V.M., Magalhães T.P., Almeida C. 2006b. Icnofósseis da Formação Santa Justa (Arenigiano, Ordovícico Inferior) no Vale do Paiva (Arouca) e a sua contribuição para o Património Paleontológico nacional. In: Mirão, J. \& Balbino A. (coords.). Livro de resumos do VII Congresso Nacional de Geologia, Universidade de Évora, Estremoz.

Scheffler M. S., Martins R. G., Kashimoto M. E., Oliveira M. A. 2010. Revisão sobre a Paleontologia no Estado do Mato Grosso do Sul: fósseis e afloramentos descritos. Brazilian Geographical Journal: Geosciences and Humanities Research $\mathrm{Me}$ dium, 1:65-99.

Schmitz P., Rogge J.H., Rosa A.O., Beber M.V. 1998. Aterros indígenas no Pantanal do Mato Grosso do Sul. Pesquisas, antropologia, 54.
Schobbenhaus C., Silva C.R. 2012. Geoparques do Brasil: propostas. Schobbenhaus C., e Silva C.R. ( Rio de Janeiro: CPRM. v.1. 748 p.

Silveira A.C., Silva A. C., Cabral N. R. A. J., Schiavetti A. 2012. Análise de efetividade de manejo do Geopark Araripe - Estado do Ceará. Geociências, 31(1):117-128.

Unesco. United Nations Educational, Scientific And Cultural Organization. 2010. World Heritage. URL:<http://whc.unesco.org/en/about/> Acesso 12.08.2013.

Unesco. 2010. United Nations Educational, Scientific and Cultural Organization. Guidelines and Criteria for National Geoparks seeking UNESCO's assistance to join the Global Geoparks Network (GGN). 12 p. URL: < http://www.globalgeopark.org/UploadFiles/2012_9_6/GGN2010.pdf> Acesso 17.07.2013.

Vilas-Boas M. P. 2012. Património paleontológico do Geopark Araripe (Ceará, Brasil): análise e propostas de conservação. 2012. Universidade do Minho 196p. (Dissert. Mestrado).

Zaine M.F. 1991. Análise dos fósseis de parte da Faixa Paraguai (MS, MT) e seu contexto temporal e paleoambiental. Inst. Geoc. USP. (Tese Dout.).

Zouros N. The European Geoparks Network: Geological heritage protection and local development. Episodes: Journal of International Geoscience, 27(3):165-171.

RESUMO: Geoparque é um conceito estabelecido pela UNESCO, mundialmente disseminado, para áreas demarcadas de expressiva beleza cênica e biodiversidade, patrimônio geológico, geralmente sob influência de populações humanas em um contexto de desenvolvimento econômico sustentável. Contudo, no Brasil esse conceito ainda é pouco difundido. Diante disso, este trabalho tem por vistas (1) refletir e discutir sobre o conceito de geoparque, por meio de comparações a programas bem sucedidos, frente uma das áreas candidatas no Brasil, "Geoparque Bodoquena-Pantanal"- MS; e (2) propor materiais didáticos que podem ser utilizados em espaços de ensino. A iniciativa da rede mundial de geoparques, estabelecida pela UNESCO, é capaz de impulsionar o desenvolvimento econômico e científico. Contudo, necessita de um bom planejamento e adequada equipe interdisciplinar. 0 até então único geoparque brasileiro (Araripe) mostra-se capaz de florescer e se desenvolver, mesmo em um contexto de problemas como tráfico de fósseis e pobreza. A área candidata no MS apresenta localidades com populações que desconhecem o conceito e que necessitam de intervenções educativas e sociais para resoluções de tais deficiências.

PALAVRAS-CHAVE: Geoparques, Geoconservação, Divulgação em Paleontologia; "Geoparque Bodoquena-Pantanal”, Geoparque Araripe. 